\title{
Expression profiles analysis identifies the values of carcinogenesis and the prognostic prediction of three genes in adrenocortical carcinoma
}

\author{
ZHIPENG GAO ${ }^{1,2}$, XIAOJUN MAN ${ }^{1,2}$, ZHENHUA LI $^{1,2}$, JIANBIN BI $^{1,2}$, XIANKUI LIU $^{1,2}$, \\ ZELIANG $\mathrm{LI}^{1,2}$, YUYAN ZHU ${ }^{1,2}$, ZHE ZHANG ${ }^{1,2}$ and CHUIZE KONG ${ }^{1,2}$ \\ ${ }^{1}$ Department of Urology, The First Hospital of China Medical University; ${ }^{2}$ Institute of Urology, \\ China Medical University, Shenyang, Liaoning 110001, P.R. China
}

Received October 6, 2018; Accepted February 13, 2019

DOI: 10.3892/or.2019.7021

\begin{abstract}
Adrenocortical carcinoma (ACC) is a rare disease associated with a poor prognosis. Furthermore, the underlying molecular mechanism of carcinogenesis is poorly understood, and prognostic prediction of ACC has low accuracy. In the present study, a bioinformatics approach was used to investigate the molecular mechanisms and prognosis of ACC. Samples of adrenal tumors were collected from patients undergoing adrenalectomy at the Department of Urology, the First Hospital of China Medical University. The analyzed gene datasets were downloaded from the Gene Expression Omnibus and The Cancer Genome Atlas (TCGA) database. Following this, the differentially expressed genes (DEGs) were included in Gene Ontology enrichment, and Kyoto Encyclopedia of Genes and Genomes (KEGG) pathway, protein-protein interaction network and survival analyses. MTT colorimetric assays, colony formation assays and 5-ethynyl-20-deoxyuridine incorporation assays were also conducted to evaluate ACC cell proliferation. The identified DEGs included 20 downregulated genes and 51 upregulated genes, which were highly associated with the cell cycle, organelle fission, chromosome segregation, cell division and spindle stability. The top 14 hub genes were subsequently confirmed by reverse transcription-quantitative polymerase chain reaction in ACC and adrenocortical adenoma samples. It was identified that the nuclear division cycle 80 , cyclin B2 and topoisomerase 2- $\alpha$ may serve important roles in adrenocortical tumor development. Furthermore, these
\end{abstract}

Correspondence to: Dr Chuize Kong or Dr Zhe Zhang, Department of Urology, The First Hospital of China Medical University, 155 North Nanjing Street, Heping, Shenyang, Liaoning 110001, P.R. China

E-mail: kongchuize_cmu@sina.cn

E-mail: zhezhangcmu@qq.com

Key words: adrenocortical carcinoma, differentially expressed genes, protein-protein interaction network, carcinogenesis, prognostic prediction three genes predicted overall survival and recurrence-free survival in patients with ACC from the TCGA cohort. The findings identified three novel genes that have important roles in carcinogenesis and in the prognostic prediction of ACC.

\section{Introduction}

The pathogenic mechanisms of adrenocortical tumors (ACTs) are complex and heterogeneous. The most common ACT is benign and is typically diagnosed incidentally (1). The aggressive forms of ACTs include adrenocortical carcinomas (ACCs), which has an incidence of 0.5 to 2 cases per million per year (1). ACC has a high mortality, with 5-year survival rates varying between 16 and $40 \%$, and is largely dependent on its stage at diagnosis (2). ACC is a highly aggressive tumor that has a poor prognosis, in part because various ACCs cannot be detected prior to the advanced stage (1). Although these types of cancer are commonly associated with a poor outcome, it is difficult to predict the prognosis $(1,3)$. The active role of insulin-like growth factor 2 (IGF2) and Ki-67 in differentiating ACCs from adrenocortical adenomas (ACAs) has been reported (4). A previous study has confirmed the active role of IGF2 in adrenocortical tumor growth (5). It has been identified that cyclin-dependent kinase inhibitor $2 \mathrm{~A}, \mathrm{RB}$ transcriptional corepressor 1 , multiple endocrine neoplasia 1 , zinc and ring finger 3, death-associated protein 6, ERT and mediator complex subunit 12 were driver genes in the transformation of ACA to ACC $(6,7)$. TP53 and catenin $\beta 1$ mutations have been reported in ACT, and are associated with tumor progression (8-10). Although there are multiple reports on ACC, the molecular mechanism underlying the molecular events accounting for carcinogenesis in ACC has not been completely elucidated. Additionally, this information is critical for allowing clinicians to make appropriate decisions and predictions of ACC survival. Therefore, further molecular level studies, including studies of genes and proteins focused on carcinogenesis and the prognostic prediction of ACC, are required.

The Gene Expression Omnibus (GEO, http://www.ncbi. nlm.nih.gov/geo/), an international public repository, consists of various high-throughput functional genomic datasets (11). The Cancer Genome Atlas (TCGA) provides multidimensional 
maps of genomic and survival information for 33 types of cancer (http://cancergenome.nih.gov/) (12). In the present study, the associated data (patients gene chip and prognostic information) were downloaded from these two datasets. However, the data stored in public databases are limited and are characterized by inconsistent results. Therefore, integrated bioinformatics methods were combined with expression profiling techniques to overcome these disadvantages in the present study.

In the present study, differentially expressed genes (DEGs) between ACC and ACA were identified, and functional analyses were subsequently performed. Gene ontology (GO) terms, Kyoto Encyclopedia of Genes and Genomes (KEGG) pathways and protein-protein interactions (PPIs) of DEGs associated with ACC were performed, particularly for genes associated with the cell cycle, organelle fission, chromosome segregation, cell division and spindle stability. To determine the role of final core genes in carcinogenesis and the prognostic prediction of ACC, the effects of genes associated with cell proliferation and the cell cycle that were silenced in NCI-H295R cells were assessed. The present study provides a further understanding of ACC, carcinogenesis and the basis for prognostic predictions, paving the way for future studies. The prognostic signature of the three genes was successfully validated in another independent cohort from TCGA.

\section{Materials and methods}

Preprocessing of gene expression microarray data, identification of DEGs and prognostic information. In the present study, gene microarray datasets comparing the gene expression profiles between ACC and ACA were downloaded from the GEO (http://www.ncbi.nlm.nih.gov/gds/). The accession numbers were GSE12368, GSE10927 and GSE14922. The microarray data of GSE12368 and GSE10927 were assessed using the GPL570 [HG-U133_Plus_2] Affymetrix Human Genome U133 Plus 2.0 Array (http://www.affymetrix. com/index.affx). The microarray data of GSE14922 were assessed using the GPL6480. The gene microarray data comprised 47 malignant tissue samples from patients with ACC and 46 adrenocortical adenomas tissue samples from surgical specimens. CEL files in different databases were converted to expression measures and normalized via the affy package in $\mathrm{R}$ (13). The aberrantly expressed mRNAs were subsequently calculated using the Limma package (14), based on the Benjamini and Hochberg procedure (14). DEGs between ACC and NAC tissues were defined by the cut-off criterion of fold change $>2$ and a $\mathrm{P}$-value of $<0.05$. The intersect function in $\mathrm{R}$ was applied to identify the common DEGs among GSE12368, GSE10927 and GSE14922. A Venn diagram was generated using the VennDiagram $\mathrm{R}$ package. The detailed survival information of a cohort of 76 patients with ACC was downloaded from the TCGA dataset.

GO and KEGG pathway analysis of the DEGs. Database for Annotation, Visualization and Integrated Discovery (DAVID) (http://david.abcc.ncifcrf.gov/) $(15,16)$ was used for functional annotation of DEGs, gene functional classification and gene ID conversion. DAVID was used to generate the official gene symbols for DEGs and to perform the GO and KEGG pathway analyses. The online website KOBAS 3.0 (http://kobas.cbi. pku.edu.cn) was used to perform the pathway enrichment analysis of the DEGs. Once the list of DEGs was submitted to the database, the GO and KEGG pathways were obtained. The false discovery rate of the q-value was adjusted to 0.05 , and a $\mathrm{P}<0.05$ was considered the cut-off criterion.

PPI network construction. The PPI network of the DEGs was constructed using Cytoscape software (version 3.5.1, available online: http://www.cytoscape.org/) (17). Once the DEGs were entered into the Search Tool for the Retrieval of Interacting Genes (STRING) online database (http://string-db.org), the PPI network was constructed by searching for known interactions. The gene-gene interactions whose integrated scores were $>0.9$ (the default threshold in the STRING database) with a fold change $>2$ were selected to construct the PPI network. In addition, cluster analysis was performed for genes with $\mathrm{P}<0.05$. The Cytoscape MCODE plugin was applied to search clustered subnetworks of highly intraconnected nodes from the PPI network complex with the default parameters (degree cut-off $\geq 2$, node score cut-off $\geq 0.2, \mathrm{~K}$-score $\geq 2$ and maximum depth $=100)$.

Patients and tumor samples. Samples of adrenal tumors were collected from patients undergoing adrenalectomy at the Department of Urology, the First Hospital of China Medical University (Shenyang, China) between July 2001 and July 2015. The present study was approved by the Ethics Committee of the First Hospital of China Medical University. Consent for the use of pertinent patient records and samples was obtained from the institutional ethics review board of the First Hospital of China Medical University and the patients. A total of 20 ACA samples were randomly selected as control samples from 1,365 patients. with ACA who underwent surgical removal of adrenocortical tumors. Clinicopathological characteristics are presented in Table SI. Experimental samples from a total of 15 patients with ACC were available at the Department of Urology between July 2001 and July 2015. All 1,365 samples included in the present study and the subset used for the further analysis were obtained retrospectively for analysis only. Diagnosis of ACCs and ACAs was performed based on the histopathologic criteria (Weiss score $\geq 3$ and $<3$, respectively) proposed by Weiss et al (18) and the modification proposed by Aubert et al (19). There were no oncocytic variant ACCs in the cohort. All tumor samples were derived from the primary surgery. There was no discrepancy between the two pathologists who independently classified the histopathological slides.

Cell culture and small interfering (si)RNA transfection. DNA topoisomerase $2 \alpha$ (TOP2A), cyclin B2 (CCNB2), NDC80 and control siRNAs (human TOP2A-siRNA, CCNB2-siRNA, NDC80-siRNA and control-siRNA) were obtained from Shanghai GenePharma Co., Ltd. (Shanghai, China). The control-siRNAs in the present study were scrambled controls. Their sequences are indicated in Table I. NCI-H295R cells were cultured in $60-\mathrm{cm}^{2}$ dishes at $37^{\circ} \mathrm{C}$ in a humidified incubator at $5 \% \mathrm{CO}_{2}$. Cells were treated with Dulbecco's modified Eagle medium (DMEM)/F12 (Gibco; Thermo Fisher Scientific, Inc. Waltham, MA, USA) supplemented with $2.5 \%$ Nu-serum I (Corning Inc., Corning, NY, USA), $1 \%$ 
Table I. Target gene siRNAs sequences.

\begin{tabular}{lc}
\hline Target genes & Sequence (5'-3') \\
\hline TOP2A-siRNA & UUCACGCACAUCAAAGUUGGG \\
CCNB2-siRNA & GGAUCGAUUUUUACAGGUUTT \\
NDC80-siRNA & GCAGCCUUAGUUUGGCUAATT \\
Negative & UUCUCCGAACGUGUCACGUTT \\
control-siRNA & \\
\hline
\end{tabular}

TOP2A, DNA topoisomerase $2 \alpha$; CCNB2, cyclin B2; NDC80, kinetochore complex component; si, small interfering.

ITS+ Premix (Corning Inc.), 1\% L-glutamine and 1\% penicillin-streptomycin (Gibco; Thermo Fisher Scientific, Inc.). It was transfected with double-stranded siRNA oligomers using Lipofectamine 3000 Transfection Reagent (Thermo Fisher Scientific, Inc.) according to the manufacturer's instructions. The amount of siRNAs that were used in the transfection experiments was $2.64 \mu \mathrm{g}$. Following transfection, cells were cultured for $48 \mathrm{~h}$ to measure their mRNA levels.

$R N A$ isolation and reverse transcription-quantitative polymerase chain reaction $(R T-q P C R)$. Following surgical resection, ACC and ACA tissue fragments were immediately frozen in liquid nitrogen and stored at $-80^{\circ} \mathrm{C}$ until total RNA extraction using TRIzol reagent (Invitrogen; Thermo Fisher Scientific, Inc.). Total RNA was extracted from cultured cells with TRIzol reagent (Invitrogen; Thermo Fisher Scientific, Inc.) according to the manufacturer's instructions. RT of RNA was performed using a high-capacity cDNA reverse transcription kit (Applied Biosystems; Thermo Fisher Scientific, Inc.). RT-qPCR was performed using LightCycler 480 SYBR-Green (Roche Molecular Systems, Inc., Pleasanton, CA, USA) and the corresponding dissociation protocol were used for gene amplification; negative controls contained water instead of first-strand cDNA. The reaction system was maintained at $55^{\circ} \mathrm{C}$ for $2 \mathrm{~min}$ and heated to $95^{\circ} \mathrm{C}$ for $10 \mathrm{~min}$, followed by 35 cycles of denaturing the mixture at $95^{\circ} \mathrm{C}$ for $15 \mathrm{sec}$, annealing at $60^{\circ} \mathrm{C}$ for $30 \mathrm{sec}$ and extension at $72^{\circ} \mathrm{C}$ for $30 \mathrm{sec}$. The relative levels of expression were quantified and analyzed using SDS 2.3 software (Applied Biosystems; Thermo Fisher Scientific, Inc.). Each sample was normalized to its $\beta$-actin content. The final results were expressed as n-fold differences in gene expression relative to $\beta$-actin and a calibrator, calculated using the $2^{-\Delta \Delta \mathrm{Cq}}$ method (20). The primer sequences of 14 hub genes and $\beta$-actin are indicated in Table II. Three independent experiments were performed to analyze the relative gene expression, and each sample was examined in triplicate.

3-(4,5-Dimethylthazol-2-yl)-2,5-diphenyltetrazolium bromide (MTT) assay. Si-TOP2A, Si-CCNB2, Si-NDC80, Si-Control and MOCK (only transfection reagents were added) cells were plated onto 96 -well plates at a density of $3 \times 10^{3}$ cells/well. The three replicates were performed for each group (Si-TOP2A, $\mathrm{Si}-\mathrm{CCNB} 2, \mathrm{Si}-\mathrm{NDC} 80$ and Si-Ctrl group) cultured in the complete DMEM/f12 medium at $37^{\circ} \mathrm{C}$ under a humidified atmosphere containing $5 \% \mathrm{CO}_{2}$. At $0,24,48$ and $72 \mathrm{~h}$ of incubation, cell proliferation was measured following the addition of $0.5 \mathrm{mg} / \mathrm{ml}$ MTT solution (Sigma-Aldrich; Merck KGaA, Darmstadt, Germany). The medium was replaced with $100 \mathrm{ml}$ of dimethyl sulfoxide (Sigma-Aldrich; Merck KGaA) and samples were vortexed for $10 \mathrm{~min}$ following $4 \mathrm{~h}$ of incubation. The absorbance was measured at a wavelength of $490 \mathrm{~nm}$ using a plate reader (model 680; Bio-Rad Laboratories, Inc., Hercules, CA, USA). Each proliferation assay was performed in triplicate.

Colony formation assay. NCI-H295R cells $\left(1 \times 10^{3}\right)$ were seeded in 6-well plates for 2 weeks and stained for 5 min at room temperature with Giemsa. The number of foci containing $>100$ cells was counted under a light microscope (magnification, x100). Each experiment was performed in triplicate.

5-Ethynyl-20-deoxyuridine (EdU) incorporation assay. Following transfection for $36 \mathrm{~h}$, cells were trypsinized and resuspended in 96-well plates at $5 \times 10^{3}$ cells/well (after the cells had been adhered). Following this, cells were exposed to $50 \mu \mathrm{mol} / 1$ of EdU (Guangzhou RiboBio Co., Ltd., Guangzhou, China) for an additional $8 \mathrm{~h}$ at $37^{\circ} \mathrm{C}$. The three replicates were performed for each group. Cells were fixed with $4 \%$ formaldehyde for $15 \mathrm{~min}$ and treated with $0.5 \%$ Triton X-100 for $10 \mathrm{~min}$ at room temperature. Following three wash steps with phosphate buffered saline, the cells of each well were treated with $100 \mu 1$ of 1X Apollo reaction cocktail (Guangzhou RiboBio Co., Ltd.) for $30 \mathrm{~min}$. Subsequently, the DNA contents of cells in each well were stained for $20 \mathrm{~min}$ at $37^{\circ} \mathrm{C}$ with $100 \mu \mathrm{l}$ of Hoechst $33342(5 \mu \mathrm{g} / \mathrm{ml})$ for $30 \mathrm{~min}$ and visualized under a fluorescent microscope (magnification, $\mathrm{x} 400$ ).

Immunohistochemistry (IHC). The expression of TOP2A, CCNB2 and NDC80 in ACC and ACA tissues was detected using an UltraSensitive Streptavidin-Peroxidase (mouse/rabbit) IHC Kit (Fuzhou Maixin Biotechnology Development Co., Ltd., Fuzhou, China) according to the manufacturer's instructions. Briefly, sections were dewaxed in xylene and ethanol. Formalin-fixed for $24 \mathrm{~h}$ at room temperature, Paraffin-embedded tissue blocks were cut to a thickness of $4 \mu \mathrm{m}$. Slices were mounted on glass slides. Immunostaining was performed using the avidin-biotin-peroxidase complex method (Ultrasensitive; Fuzhou Maixin Biotechnology Development Co., Ltd.). The sections were deparaffinized in xylene, rehydrated with graded alcohol (100, 90, 80, 70, 60 and 50\%), and then boiled in $0.01 \mathrm{M}$ citrate buffer ( $\mathrm{pH}$ 6.0) for $2 \mathrm{~min}$ in an autoclave. Peroxidase inhibitor was applied to block endogenous peroxide activity for $30 \mathrm{~min}$ at room temperature, and the sections were incubated with normal goat serum (dilution not specified in kit; Fuzhou Maixin Biotechnology Development Co., Ltd.) to reduce nonspecific binding for $30 \mathrm{~min}$. Antibody staining was performed at $4^{\circ} \mathrm{C}$ overnight. Biotinylated goat anti-mouse serum IgG was used as a secondary antibody (dilution not specified in kit; cat. no. KIT-9710; Fuzhou Maixin Biotechnology Development Co., Ltd.) for $30 \mathrm{~min}$ at room temperature. Following washing, the sections were incubated with streptavidin-biotin conjugated with horseradish peroxidase (dilution not specified in kit; cat. no. KIT-9710; Fuzhou 
Table II. Primer sequences of the 14 identified hub genes and $\beta$-actin.

\begin{tabular}{lll}
\hline Target gene & \multicolumn{1}{c}{ Forward primer sequence $\left(5^{\prime}-3^{\prime}\right)$} & Reverse primer sequence $\left(5^{\prime}-3^{\prime}\right)$ \\
\hline CDK1 & GGAAGGGGTTCCTAGTACTGC & CCATGTACTGACCAGGAGGGA \\
MAD2L1 & ACTTTTGAAACGCTTGGCGG & GAGAAGAACTCGGCCACGAT \\
BIRC5 & AGGACCACCGCATCTCTACAT & AAGTCTGGCTCGTTCTCAGTG \\
CCNB2 & CCGACGGTGTCCAGTGATTT & TGTTGTTTTGGTGGGTTGAACT \\
TPX2 & ATGGAACTGGAGGGCTTTTC & TGTTGTCAACTGGTTTCAAAGGT \\
PRC1 & ACACTCTGTGCAGCGAGTTAC & TTCGCATCAATTCCACTTGGG \\
RRM2 & CACGGAGCCGAAAACTAAAGC & TCTGCCTTCTTATACATCTGCCA \\
ASPM & GGCCCTAGACAACCCTAACGA & AGCTTGGTGTTTCAGAACATCA \\
EZH2 & AATCAGAGTACATGCGACTGAGA & GCTGTATCCTTCGCTGTTTCC \\
PBK & CCAAACATTGTTGGTTATCGTGC & GGCTGGCTTTATATCGTTCTTCT \\
NCAPG & GAGGCTGCTGTCGATTAAGGA & AACTGTCTTATCATCCATCGTGC \\
TOP2A & ACCATTGCAGCCTGTAAATGA & GGGCGGAGCAAAATATGTTCC \\
NDC80 & TGCCGACAGCTTTGATGAGA & GCAGGTGCTTGTGTTTCTCC \\
KIAA0101 & ATGGTGCGGACTAAAGCAGAC & CCTCGATGAAACTGATGTCGAAT \\
$\beta$-ACTIN & CATGTACGTTGCTATCCAGGC & CTCCTTAATGTCACGCACGA
\end{tabular}

ASPM, abnormal spindle microtubule assembly; BIRC5, baculoviral IAP repeat containing 5; CDK1, cyclin-dependent kinase 1; EZH2, enhancer of zeste 2 polycomb repressive complex 2 subunit; KIAA0101, KIAA0101 ortholog; MAD2L1, mitotic arrest deficient 2-like 1; NCAPG, non-SMC condensin I complex subunit G; PBK, PDZ binding kinase; PRC1, protein regulator of cytokinesis 1; RRM2, ribonucleotide reductase regulatory subunit M2; TPX2, microtubule nucleation factor; CCNB2, cyclin B2; TOP2A, DNA topoisomerase 2 $\alpha$; RRM2, ribonucleotide reductase regulatory subunit M2; NDC80, kinetochore complex component.

Maixin Biotechnology Development Co., Ltd.) for $30 \mathrm{~min}$ at room temperature, and immunoreaction was visualized using diaminobenzidine as a chromogen for $30 \mathrm{sec}-1 \mathrm{~min}$ at room temperature. As a control, incubation without the primary antibody or with a nonspecific serum was also performed. The paraffin-embedded tissue blocks that were cut into $4-\mu \mathrm{m}$ thick sections were also subjected to IHC with rabbit monoclonal antibody for human TOP2A (1:100 dilution; Abcam, Cambridge, UK), CCNB2 (1:100 dilution; Abcam) and NDC80 (1:100 dilution; Abcam). For both antigens, diaminobenzidine and hematoxylin were used for nuclear staining. Nuclear staining was performed by treating the slides for 2 min with hemalum, followed by $10 \mathrm{~min}$ incubation in running water to induce the color reaction. Eventually, the stained slices were dehydrated and mounted. A light microscope was used (magnification, $\mathrm{x} 400$ ).

Data analysis and statistical methods. SPSS 22.0 software (IBM Corp., Armonk, NY, USA) was used in different analyses. The datasets analyzed in the study are available in GEO (http://www.ncbi.nlm.nih.gov/geo/) and TCGA (http://cancergenome.nih.gov). The statistical significance of different experimental data was analyzed using GraphPad Prism 6.0 software (GraphPad Software, Inc., San Diego, CA, USA). Kaplan-Meier curves were used to determine survival status, and differences between groups were analyzed using the log-rank test. All data were presented as the mean \pm standard deviation. $\mathrm{P}<0.05$ was considered to indicate a statistically significant difference. Associations between variables were analyzed using Spearman's rank correlation test. The associations between variables were analyzed by Student's t-test and the $\chi^{2}$ test. Comparisons were performed for multiple means using analysis of variance followed two-way analysis of variance with Turkey's multiple comparisons. All experiments were repeated at least three times.

\section{Results}

DEGs among GSE12368, GSE10927 and GSE14922. Quality and systematic bias among original chip data were adjusted following preprocessing by the Affymetrix package in $\mathrm{R}$ language. Volcano plots were constructed to visualize the distribution of expressed genes between ACC and ACA from different studies. Significantly upregulated genes were represented by red dots, and significantly downregulated genes were indicated with green on the plots (Fig. 1A-C). The common DEGs $(\mathrm{P}<0.05$ and IFold changel $>2)$ of the three projects were demonstrated (Fig. 1D). A total of 20 significantly upregulated genes and 51 downregulated genes were acquired from the three independent cohorts and are listed in Table III.

Enriched GO terms and KEGG pathways of DEGs. STRING, DAVID and KOBAS 3.0 online websites were applied to perform GO and pathway enrichment analysis of the DEGs. The most enriched GO terms were associated with the cell cycle, including the mitotic cell cycle, mitosis, nuclear division and the $\mathrm{M}$ phase of the mitotic cell cycle. GO terms were revealed according to P-values (Fig. 2A; Table IV). DEGs were primarily enriched in retinal metabolism, metabolic pathways, tyrosine metabolism, the cell cycle and p53 signaling pathways (Fig. 2B; Table V). 

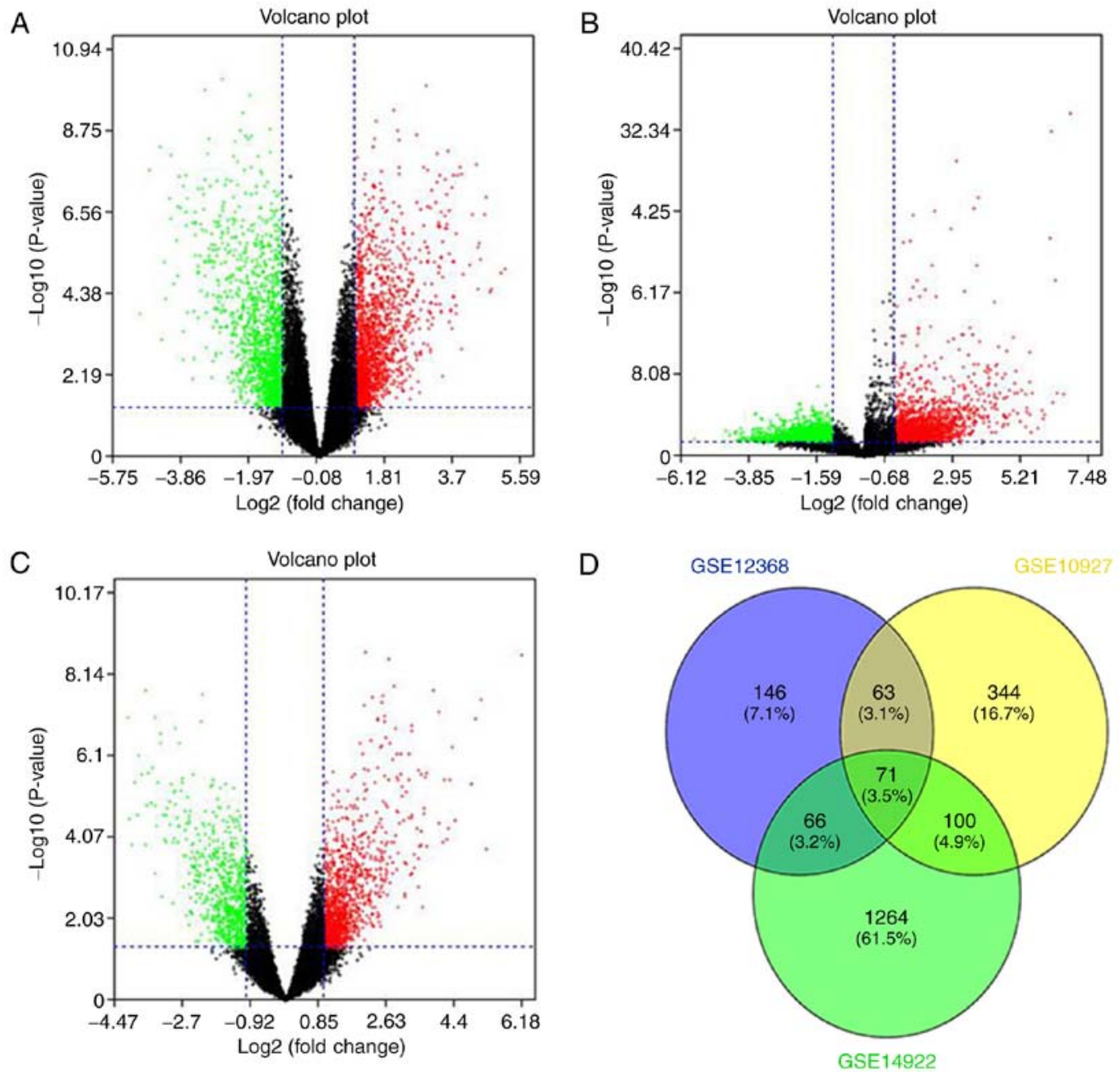

Figure 1. Volcano plots of genes that are significantly different between adrenocortical carcinoma and adrenocortical adenoma tissues. X-axis indicated the fold change (logscaled) whereas the y-axis indicated the P-values (logscaled). Each symbol represented a different gene, and the red/green color of the symbols categorize the upregulated/downregulated genes falling under different criteria (P-value and fold change threshold), respectively. $\mathrm{P}<0.05$ was considered as statistically significant, whereas fold change $=2$ was set as the threshold (A) GSE12368 (B) GSE10927 and (C) GSE14922. (D) Common differentially expressed genes among GSE12368, GSE110927 and GSE1492.

A

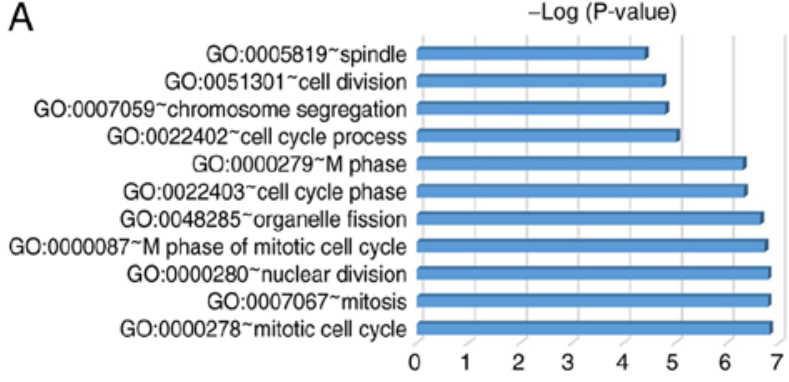

B

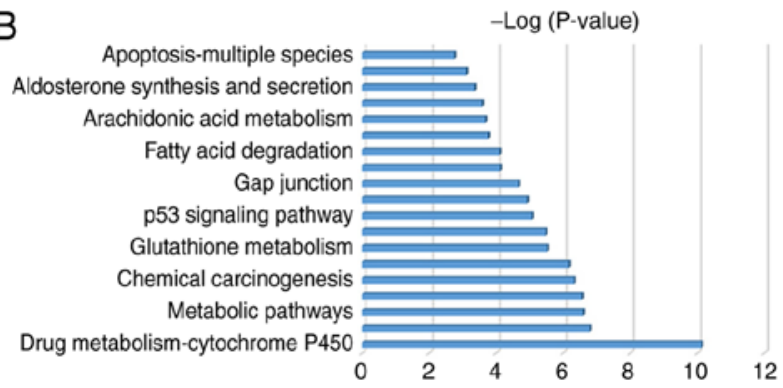

Figure 2. GO and KEGG pathway analysis of significant DEGs. (A) Significantly enriched GO categories were calculated. (B) Gene networks identified through KEGG analysis of DEGs. GO, Gene Ontology; KEGG, Kyoto Encyclopedia of Genes and Genomes; DEGs, differentially expressed genes.

Key candidate gene identification with DEGs in the PPI network. As indicated in Fig. 3A, a PPI network complex was constructed containing 176 nodes and 639 edges according to the STRING online database (available online: http://string-db. org) and Cytoscape software (version 3.5.1, available online: http://www.cytoscape.org/). The 71 DEGs screened out in all four datasets. The PPI network was performed with MCODE plugin for module analysis. The most significant module was confirmed for further pathway analyses according to the degree (Fig. 3B) and the 14 genes involved that were defined as key candidate genes.

$R T-q P C R$ validation of core genes. Based on the PPI results and the information of cancer-associated genes, RT-qPCR was performed to confirm the selected 14 core genes that were the most meaningful DEGs for distinguishing ACC and ACA. 
Table III. Common DEGs identified among GSE12368, GSE10927 and GSE14922.

A, Downregulated DEGs

Gene names

KCNQ1, HSD3B2, ADH1B, CYP11B2, NR4A2, NOV, MFAP5, AADAC, FBLN1, PDGFRA, ABCA8, AOX1, DCN, SPON1, LMOD1, CSDC2, HOPX, HTR2B, VSNL1, C7, RAI2, NPY1R, CYP11B1, FBLN5, CXCL12, NDUFC2-KCTD14, KCTD14, SORBS2, KCNJ5, PDGFD, OGN, GSTT1, CHRDL1, DNAJC12, GGT5, COL4A4, KIF5C, CDKN1C, FNDC4, ABLIM1, PTGDS, TKFC, HEPH, ALAS1, APOD, ALDH1A1, HOXA5, SORBS1, ABCB1, ABCB4, ABCB1, FMO2 and SCG2.

\section{B, Upregulated DEGs}

GINS1, CCNB2, MAD2L1, PBK, APOBEC3B, EZH2, BIRC5, NDC80, NCAPG, KIAA0101, TPX2, ANGPT2, RRM2, TOP2A, SMC3, PRC1, PMAIP1, INS-IGF2, IGF2, ASPM and CDK1.

DEGs, differentially expressed genes; KCNQ1, potassium voltage-gated channel subfamily Q member 1; HSD3B2, hydroxy-delta-5-steroid dehydrogenase, 3 beta- and steroid delta-isomerase 2; ADH1B, alcohol dehydrogenase 1B (class I), beta polypeptide; CYP11B2, cytochrome P450 family 11 subfamily B member 2; NR4A2, nuclear receptor subfamily 4, group A, member 2; NOV, nephroblastoma overexpressed; MFAP5, microfibril associated protein 5; AADAC, microfibril associated protein 5; FBLN1, fibulin 1; PDGFRA, platelet derived growth factor receptor alpha; ABCA8, ATP binding cassette subfamily A member 8; AOX1, aldehyde oxidase 1; DCN, decorin; SPON1, spondin 1; LMOD1, leiomodin 1; CSDC2, cold shock domain containing C2; HOPX, HOP homeobox; HTR2B, 5-hydroxytryptamine (serotonin) receptor 2B; VSNL1, visinin-like 1; C7, complement C7; RAI2, retinoic acid induced 2; NPY1R, neuropeptide Y receptor Y1; CYP11B1, cytochrome P450 family 11 subfamily B member 1; FBLN5, fibulin 5; CXCL12, C-X-C motif chemokine ligand 12; NDUFC2-KCTD14, NDUFC2-KCTD14 readthrough; SORBS2, sorbin and SH3 domain containing 2; KCNJ5, potassium voltage-gated channel subfamily J member 5; PDGFD, platelet derived growth factor D; OGN, osteoglycin; GSTT1, glutathione S-transferase theta 1; CHRDL1, chordin-like 1; DNAJC12, DnaJ heat shock protein family (Hsp40) member C12; GGT5, $\gamma$-glutamyltransferase 5; COL4A4, collagen type IV $\alpha 4$ chain; KIF5C, kinesin family member 5C; CDKN1C, cyclin-dependent kinase inhibitor 1C; FNDC4, fibronectin type III domain containing 4; ABLIM1, actin binding LIM protein 1; PTGDS, prostaglandin D2 synthase; TKFC, triokinase and FMN cyclase; HEPH, hephaestin; ALAS1, 5'-aminolevulinate synthase 1; APOD, apolipoprotein D; ALDH1A1, aldehyde dehydrogenase 1 family member A1; HOXA5, homeobox A5; SORBS1, sorbin and SH3 domain containing 1; ABCB1, ATP binding cassette subfamily B member 1; ABCB4, ATP binding cassette subfamily B member 4; FMO2, flavin containing monooxygenase 2; SCG2, secretogranin II; GINS1, GINS complex subunit 1; CCNB2, cyclin B2; MAD2L1, mitotic arrest deficient 2-like 1; PBK, PDZ binding kinase; APOBEC3B, apolipoprotein B mRNA editing enzyme catalytic subunit 3B; EZH2, enhancer of zeste 2 polycomb repressive complex 2 subunit; BIRC5, baculoviral IAP repeat containing 5; NDC80, kinetochore complex component; NCAPG, non-SMC condensin I complex subunit G; KIAA0101, KIAA0101 ortholog; TPX2, microtubule nucleation factor; ANGPT2, angiopoietin 2; RRM2, ribonucleotide reductase regulatory subunit M2; TOP2A, DNA topoisomerase II $\alpha$; SMC3, structural maintenance of chromosomes 3; PRC1, protein regulator of cytokinesis 1; PMAIP, phorbol-12-myristate-13-acetate-induced protein 1; INS-IGF2, INS-IGF2 readthrough; ASPM, abnormal spindle microtubule assembly; CDK1, cyclin-dependent kinase 1 .

Table IV. Significant GO terms of differentially expressed genes in adrenocortical carcinoma.

\begin{tabular}{llrl}
\hline Term & \multicolumn{1}{c}{ Description } & Count & P-value \\
\hline GO:0000278 & Mitotic cell cycle & 12 & $1.50 \times 10^{-07}$ \\
GO:0007067 & Mitosis & 10 & $1.61 \times 10^{-07}$ \\
GO:0000280 & Nuclear division & 10 & $1.61 \times 10^{-07}$ \\
GO:0000087 & M phase of mitotic cell cycle & 10 & $1.88 \times 10^{-07}$ \\
GO:0048285 & Organelle fission & 10 & $2.26 \times 10^{-07}$ \\
GO:0022403 & Cell cycle phase & 12 & $4.63 \times 10^{-07}$ \\
GO:0000279 & M phase & 11 & $4.87 \times 10^{-07}$ \\
GO:0022402 & Cell cycle process & 12 & $9.44 \times 10^{-06}$ \\
GO:0007059 & Chromosome segregation & 6 & $1.56 \times 10^{-05}$ \\
GO:0051301 & Cell division & 9 & $7.76 \times 10^{-05}$ \\
GO:0005819 & Spindle & 7 & $3.81 \times 10^{-05}$ \\
\hline
\end{tabular}

GO, Gene Ontology.

There were only three genes, namely TOP2A, CCNB2 and NDC80, whose RT-qPCR results were consistent with the PPI results from the microarray data $(\mathrm{P}<0.05$; Fig. 4A-C). All three genes were upregulated in the ACC group compared with the 


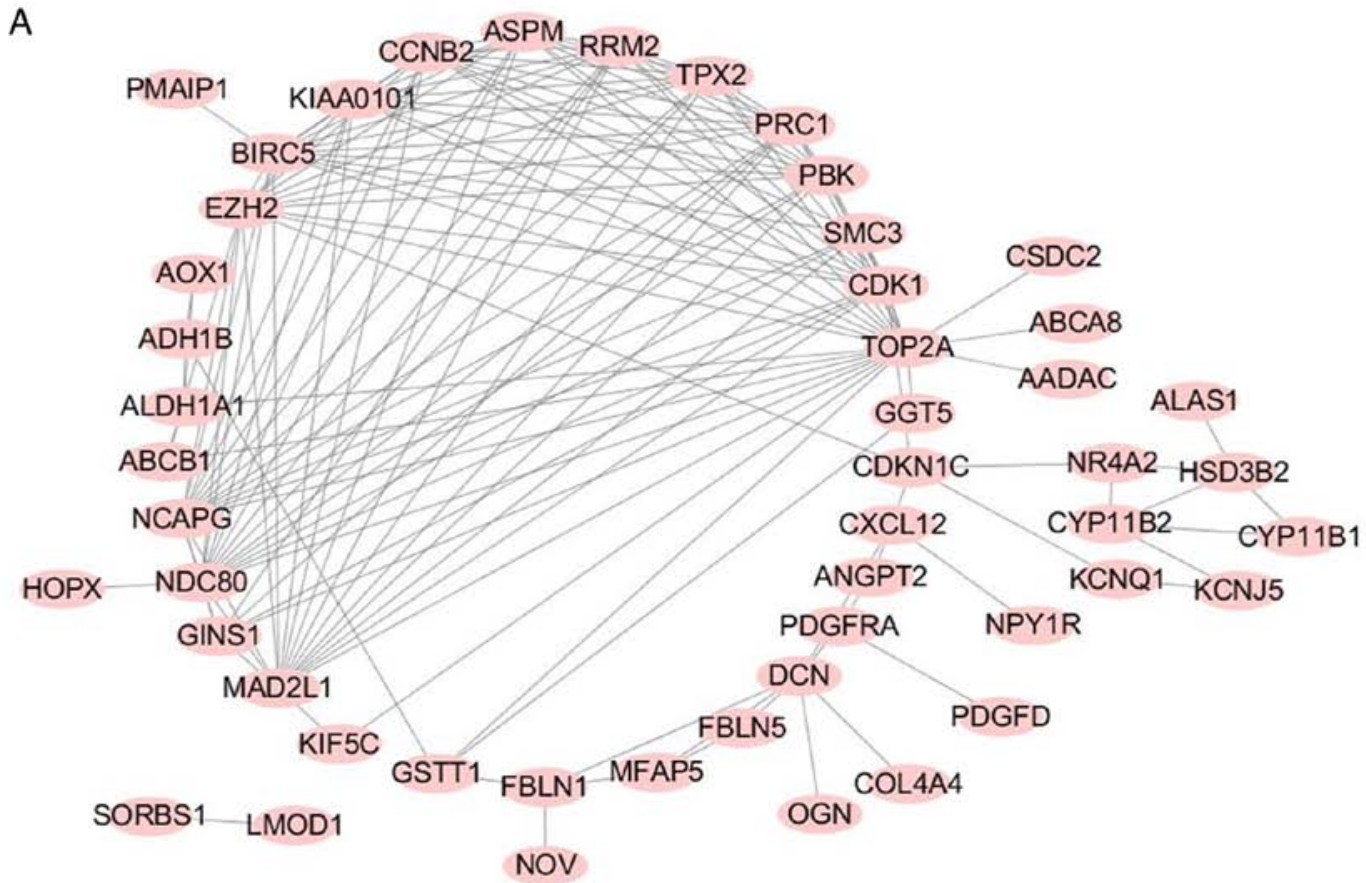

B

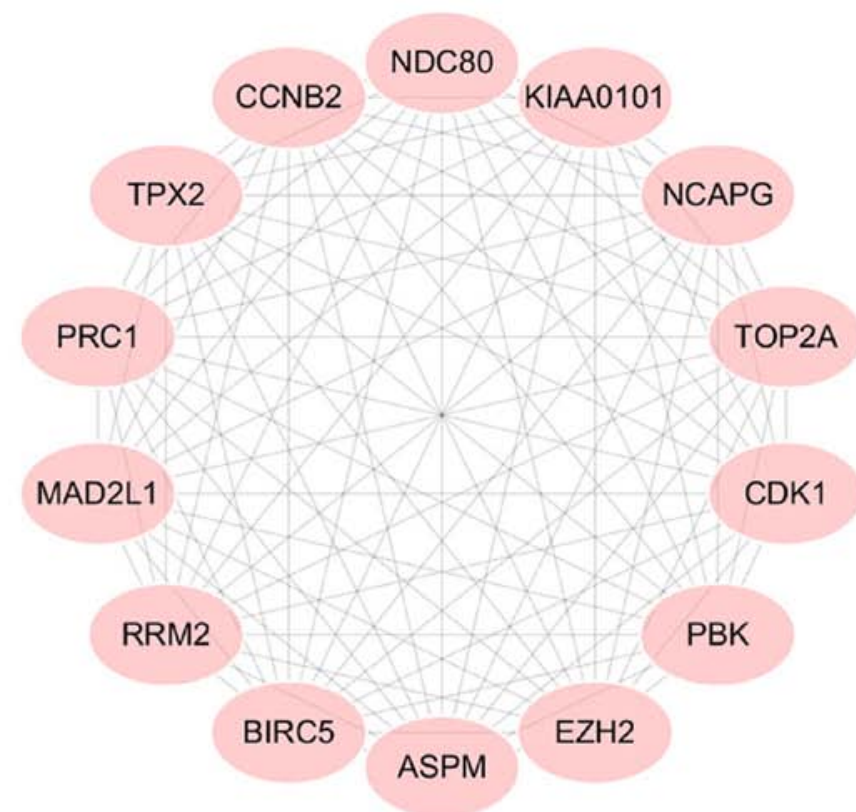

Figure 3. Constructed protein-protein interaction networks of the DEGs and modular analyses. (A) Protein-protein interaction network of the DEGs was constructed using online Search Tool for the Retrieval of Interacting Genes database and Cytoscape software. (B) Highlighted circle areas, which was the most significant module, was analyzed by MCODE plugin. One sub-network was identified using the Cytoscape MCODE plug-in. DEGs, differentially expressed genes.
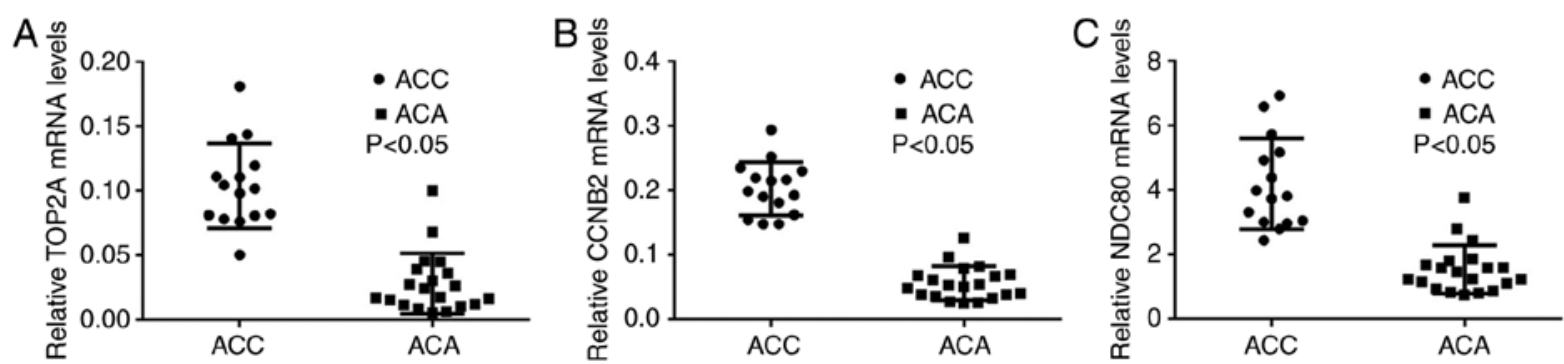

Figure 4. mRNA expression levels of (A) TOP2A, (B) CCNB2 and (C) NDC80 between ACC and ACA samples. ACC, adrenocortical carcinoma; ACA, adrenocortical adenoma; TOP2A, DNA topoisomerase $2 \alpha$; CCNB2, cyclin B2. 

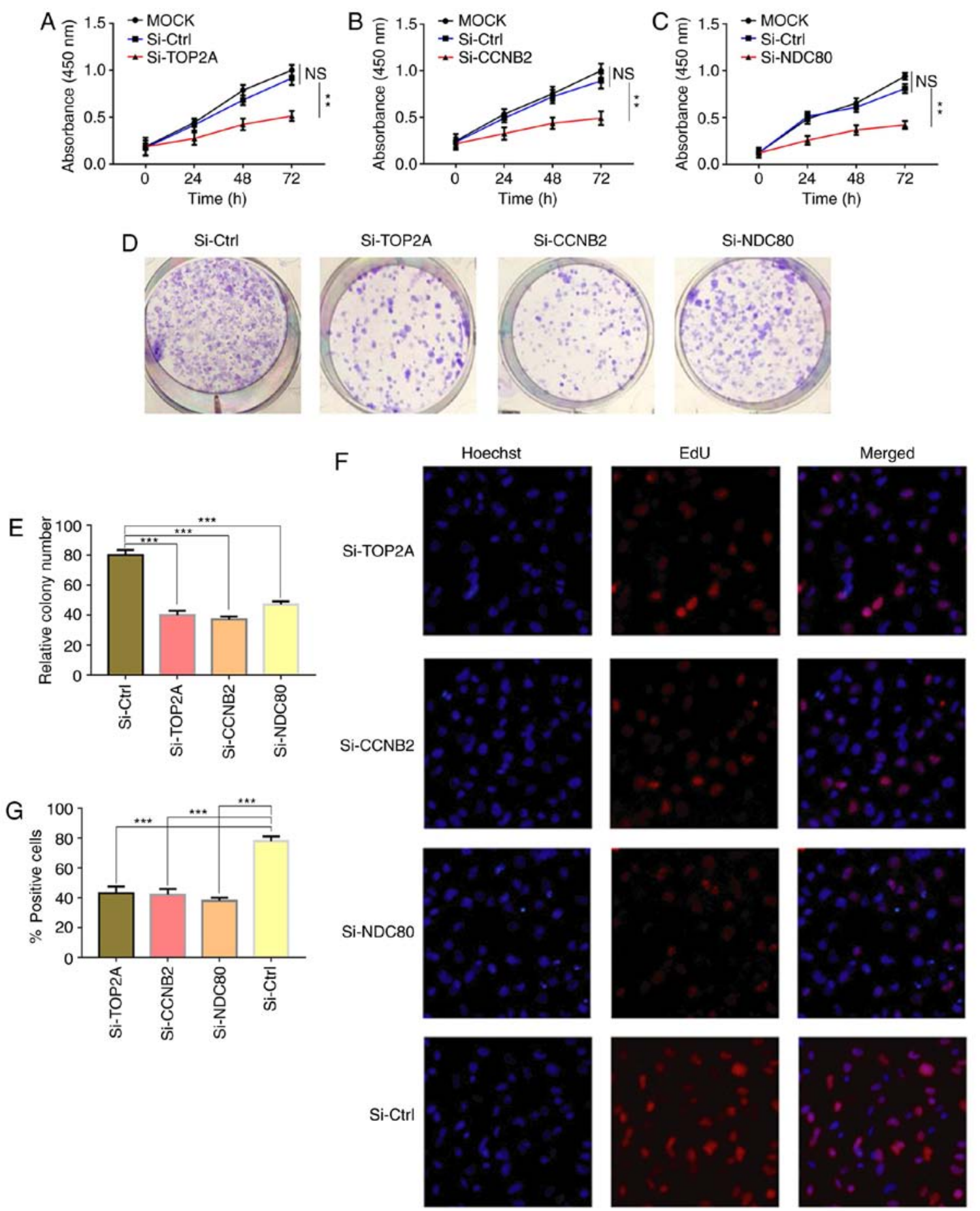

Figure 5. Inhibition of NCI-H295R cell proliferation by downregulation of TOP2A, CCNB2 and NDC80. (A-C) Proliferation rates of NCI-H295R cells in the si-TOP2A, si-CCNB2 and si-NDC80 groups were significantly decreased compared with the control groups at the same time points. (D) Effects of the silencing TOP2A, CCNB2 and NDC80 on NCI-H295R cell colony formation. (E) Statistical results of NCI-H295R cell colony formation. (F) EdU incorporation assays (magnification, $\mathrm{x} 400$ ). (G) Statistical results of NCI-H295R cell EdU incorporation assays. Data were presented as the mean \pm standard deviation. ${ }^{* *} \mathrm{P}<0.01$ and ${ }^{* * *} \mathrm{P}<0.001$ as indicated. TOP2A, DNA topoisomerase $2 \alpha$;CNB2, cyclin B2; si, small interfering; Ctrl, control; EdU, 5-ethynyl-20-deoxyuridine; NS, not significant.

ACA group. RT-qPCR results of the remaining 11 genes that exhibited no statistical significance between ACC and ACA groups were demonstrated in Fig. S1.

Knockdown of TOP2A CCNB2 and NDC80 in NCI-H295R cells hinders cell proliferation. To investigate the involved roles of TOP2A, CCNB2 and NDC80 in tumor progression,
NCI-H295R cells were transfected with the siRNAs of the above three genes, as well as their respective negative controls. The targeting siRNAs (Si-TOP2A, Si-CCNB2, Si-NDC80) knocked out the corresponding mRNAs expression levels in NCI-H295R cells. The transfection efficacy was confirmed by RT-qPCR (Fig. S2). The expression level of each corresponding mRNA expression levels were reduced 
Table V. Significant pathways involved in the differentially expressed genes in adrenocortical carcinoma.

\begin{tabular}{llrr}
\hline ID & \multicolumn{1}{c}{ Term } & Count & P-value \\
\hline hsa00982 & Drug metabolism-cytochrome P450 & 7 & $7.55 \times 10^{-11}$ \\
hsa00830 & Retinol metabolism & 5 & $1.61 \times 10^{-07}$ \\
hsa01100 & Metabolic pathways & 13 & $2.56 \times 10^{-07}$ \\
hsa00980 & Metabolism of xenobiotics by cytochrome P450 & $2.77 \times 10^{-07}$ \\
hsa05204 & Chemical carcinogenesis & 5 & $4.79 \times 10^{-07}$ \\
hsa00350 & Tyrosine metabolism & 5 & $6.87 \times 10^{-07}$ \\
hsa00480 & Glutathione metabolism & 4 & $3.00 \times 10^{-06}$ \\
hsa04110 & Cell cycle & 4 & $3.37 \times 10^{-06}$ \\
hsa04115 & p53 signaling pathway & 5 & $8.69 \times 10^{-06}$ \\
hsa01524 & Platinum drug resistance & 4 & $1.19 \times 10^{-05}$ \\
hsa04540 & Gap junction & 4 & $2.17 \times 10^{-05}$ \\
hsa04114 & Oocyte meiosis & 4 & $7.68 \times 10^{-05}$ \\
hsa00071 & Fatty acid degradation & 4 & $7.97 \times 10^{-05}$ \\
hsa00140 & Steroid hormone biosynthesis & 3 & $1.74 \times 10^{-4}$ \\
hsa00590 & Arachidonic acid metabolism & 3 & $2.10 \times 10^{-4}$ \\
hsa00010 & Glycolysis/Gluconeogenesis & 3 & $2.62 \times 10^{-4}$ \\
hsa04925 & Aldosterone synthesis and secretion & 3 & $4.47 \times 10^{-4}$ \\
hsa04914 & Progesterone-mediated oocyte maturation & 3 & $7.66 \times 10^{-4}$ \\
\hline
\end{tabular}

by $\sim 90 \%$. Following this, MTT assays were performed to evaluate the effects of TOP2A, CCNB2 and NDC80 knockdown on cell proliferation. As indicated in Fig. 5A-C, the proliferation rates of NCI-H295R cells in the three groups were lower compared with those in the control groups at the same time points, and this difference was statistically significant $(\mathrm{P}<0.05)$, suggesting the important role of the three genes in regulating cell proliferation. Colony formation assays supported this conclusion (Fig. 5D and E). Furthermore, EdU incorporation assays revealed that knockdown of TOP2A, CCNB2 and NDC80 influenced the proliferation of NCI-H295R cells (Fig. 5F and G). These results indicated that knockdown of TOP2A, CCNB2 and NDC80 affected the proliferation of ACC cells and induced ACC cell proliferation stagnation in vitro.

Prognostic signature of the three genes from IHC results and an independent cohort in TCGA. IHC results were consistent with those of RT-qPCR. The immunostaining data regarding the expression of TOP2A, CCNB2 and NDC80 in ACC and ACA tissues were demonstrated (Fig. 6A). The expression of each protein in ACC was markedly higher compared with that in ACA. The influence of the three genes on recurrence-free survival (RFS) and overall survival (OS) were assessed by TCGA. A cohort of 76 ACC patients were enrolled to evaluate the association between the three genes and RFS time. Kaplan-Meier curve and log-rank tests revealed that the TOP2A, CCNB2 and NDC80 genes were each significantly associated with RFS (Fig. 6B-D). Similar to RFS, the association between the three genes and OS also indicated significant correlations (Fig. 6E-G). The results suggested that the high-expression group had shorter RFS and OS compared with the low-expression group for these three genes.

\section{Discussion}

For pathologists, the Weiss score is primarily used to diagnose ACTs between ACC and ACA (19). However, when the tumor is borderline (Weiss score 3), the task of diagnosing can be problematic. Although TERT promoter mutations can appear in ACCs (21), the underlying genetic alterations associated with ACC remain to be elucidated. Notably, the rapid development and wide use of microarray and high-throughput sequencing technology has revealed thousands of genetic alterations during the progression of diseases. This method can be used with the GEO database to identify the DEGs of ACC and ACA tissues. The present analysis identified 71 commonly changed DEGs integrating three original microarray datasets, including 51 significantly upregulated and 20 downregulated genes based on P-values $<0.05$. These DEGs may be important for understanding the mechanism of ACC carcinogenesis and prognostic prediction. GO analyses revealed that these DEGs were primarily associated with the mitotic cell cycle, mitosis, nuclear division and the $\mathrm{M}$ phase of the mitotic cell cycle. KEGG pathway enrichment analysis also revealed that the DEGs were predominantly enriched in retinol metabolism, metabolic pathways, tyrosine metabolism, the cell cycle and p53 signaling pathways. In addition, a PPI network was constructed to visualize the interactions among the DEGs based on the intersection of GO enrichment terms and KEGG pathways. The most significant genes in the PPI network complex were identified by a module of the Cytoscape MCODE plugin. Subsequently, 14 candidate genes were identified, suggesting their potential roles as the most essential genes in distinguishing ACC from ACA. These 14 genes were validated by RT-qPCR. Because the databases used were from Australia (GSE12368), the United States (GSE10927) 

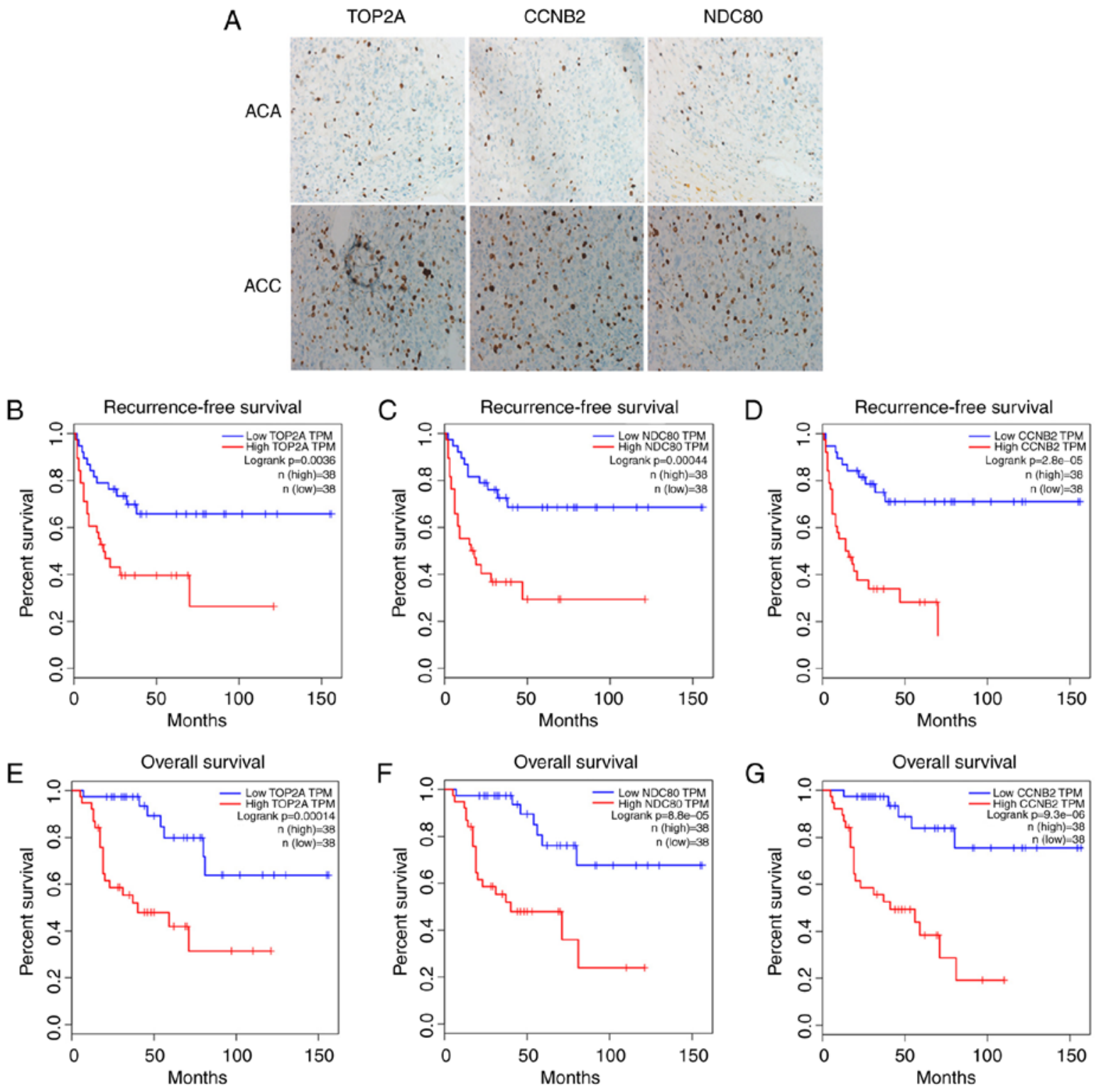

Figure 6. IHC and Kaplan-Meier analysis of patients with ACC and high or low TOP2A, CCNB2 and NDC80 expression. (A) Immunostaining data on the TOP2A, CCNB2 and NDC80 expression levels in ACC and ACA tissue (magnification, x400). (B-D) Recurrence-free survival in patients with ACC. (E-G) OS in patients with ACC. IHC, Immunohistochemistry; ACC, adrenocortical carcinoma; RFS, recurrence-free survival; OS, overall survival.

and Hungary (GSE14922), the races contained in the databases were different from the human specimens involved in the present experiments. Only TOP2A, CCNB2 and NDC80 were confirmed to be consistent with the microarray data. To our knowledge, all three genes are associated with cell proliferation and cell growth (22-24). Furthermore, TOP2A, CCNB2 and NDC80 were knocked out in the ACC cell line NCI-H295R, and MTT assays, colony formation assays and EdU incorporation assays were performed. All results demonstrated that these genes serve important roles in the process of ACC cell proliferation and growth. The results of IHC further confirmed that these three genes serve an important role in the identification of ACC and ACA. Notably, Kaplan-Meier analysis revealed that TOP2A, CCNB2 and NDC80 were correlated with OS and RFS.

The first DEG identified via microarray and RT-qPCR data was TOP2A, which is a key enzyme in DNA replication and transcription that controls or alters the topologic states of DNA (25). The gene catalyzes double-strand DNA breaks and promotes gene transcription during mitosis $(26,27)$. It was reported that TOP2A is a sensitive and specific marker in actively proliferating cells (in the late $\mathrm{S}, \mathrm{G} 2$ and $\mathrm{M}$ phases of the cell cycle), implicating its role in cancer (28). Its enzyme is a marker of cell proliferation in normal and tumor tissue (28). TOP2A was confirmed to be involved in epigenetic regulation through enhancer of zeste homolog 2, and aberrant expression of TOP2A was correlated with malignant characteristics of prostate cancer $(29,30)$. In the present study, TOP2A was upregulated in ACC compared with ACA according to microarray data, which was confirmed by RT-qPCR. Furthermore, the results of the above experiments indicated that TOP2A serves an important role in cell proliferation. Previous studies have indicated that overexpression of TOP2A is associated with shortened survival in breast, ovary, brain, skin and small cell lung cancer (31-35). In the present study, it was revealed that TOP2A may be a significant DEG between ACC and ACA. 
Thus, TOP2A may serve an important role in carcinogenesis and could be used in prognostic predictions of ACC.

CCNB2, a member of the cyclin family proteins, serves a key role in the cell proliferation and in cell cycle. CCNB2 inhibition induces cell cycle arrest, and it is overexpressed in various types of tumors, including colorectal adenocarcinoma (36), breast (37) and bladder cancer (38). Furthermore, CCNB2 overexpression is also associated with tumor progression and poor outcome in patients (23). Mechanistic research has suggested that overexpressed CCNB2 causes aurora-A-mediated Plk1 hyperactivation, bringing about accelerated centrosome separation and lagging chromosomes (39). In the present study, CCNB2 was upregulated in ACC compared with ACA based on microarray data and RT-qPCR. Additionally, in the present study, the results of the MTT, colony formation and EdU incorporation assays revealed that the proliferation rate of NCI-H295R cells was significantly reduced following CCNB2 knockdown. Therefore, it was suggested that CCNB2 may be involved in the progression of ACC.

NDC80 serves an important role in constituting the mitotic kinetochore complex (40). It is an attractive molecular target for cancer. The critical function of NDC80 for spindle checkpoint control, kinetochore functionality and cell survival has also been confirmed (41). NDC80 is mostly expressed in rapidly dividing cells, and its expression levels increase with transformation in the cell lines (42). Shortly following its identification, the function of the NDC80 protein was established to be associated with tumor formation (43). In vivo, overexpression of NDC80 has been demonstrated to contribute to tumor formation (44). Some studies have reported that targeted inhibition of NDC80 by RNA interference or small molecules effectively hinders the growth of tumors in animal models $(44,45)$. NDC80 silencing may also cause mitotic spindle checkpoint dysfunction that leads to cell proliferation (40). In the present study, NDC80 was upregulated in ACC according to microarray and RT-qPCR data. Cell proliferation were hindered in NDC80-silenced NCI-H295R cells compared with the control according to MTT, colony formation and EdU incorporation assays. Based on these findings, it was suspected that NDC80 may serve an important role in the development of ACC.

Since the number of samples enrolled in the present research was limited, there was insufficient detail to investigate the clinicopathological characteristics of the patients. The TCGA database was used to verify the prognostic value of the three-gene molecular signature. In summary, high TOP2A, CCNB2 or NDC80 expression contributes to malignant progression and poor outcomes in patients with ACC. Combining the immunohistochemical results of the three genes expressed in ACC and ACA (TOP2A, CCNB2 and NDC80) identified in the present study may be useful for distinguishing between ACC and ACA or could serve as biomarkers for survival prediction in patients with ACC. It can also be concluded that they serve an important role in understanding the progress of ACC.

Using several microarray datasets from the GEO database, a series of DEGs were obtained between ACC and ACA. These genes may be associated with the pathogenesis and progression of ACC. Following validation of the results by RT-qPCR, three DEGs were identified to be significantly associated with ACC and ACA. They may serve important roles in the pathogenesis of ACC, or they may provide new viewpoints regarding the diagnosis and prognosis of patients with adrenal cortical tumors and the clinical outcomes of ACC. The results of Colony formation assay, MTT assays and EdU assays of the three genes in NCI-H295R cells indicated the prognostic prediction and can develop the understand the of the carcinogenesis of ACC. Combined with the results of IHC, and RFS and OS from TCGA, the three genes may not only indicate the carcinogenesis of ACC but also have clinical usefulness for prognostic prediction in patients with ACC.

There are some limitations to the present study. The validation samples and the TCGA were analyzed retrospectively; therefore, the present results should be further confirmed prospectively. In the present study, ACA was defined with a Weiss score $<3$. ACC was defined with a Weiss score $>3$. The present research results are based on the traditional Weiss score without opening up a completely new diagnostic criteria. Furthermore, all three indicators in the study were highly expressed in ACC, whereas the expression in ACA was limited. Of note, the patient's follow-up information was not successfully obtained, resulting in the uncertainty of the prognostic role of these three genes in patients. Unfortunately, no clinical data regarding the patients with ACAs and ACCs were indicated in the present study, which was a further limitation.

To conclude, further work will be performed to provide some evidence that the identified potential markers may be superior to the golden standard and that when Weiss score is $\sim 3$, the expression of these markers may provide guidance for distinguishing malignant and benign tumors.

\section{Acknowledgements}

Not applicable.

\section{Funding}

The present study was supported by the Project of Liaoning Distinguished Professor [grant no. (2012)145], the Liaoning Natural Science Fund [201602830], the Shenyang Plan Project of Science and Technology (grant no. F17-230-9-08), the Shenyang Clinical Medicine Research Center [grant no. (2017)76] and the National Nature Science Foundation of China (grant no. 81672523).

\section{Availability of data and materials}

The datasets used and/or analyzed during the current study are available from the corresponding author on reasonable request.

\section{Authors' contributions}

$\mathrm{ZG}, \mathrm{XM}, \mathrm{ZhL}$ and JB wrote the manuscript and analyzed the data. ZG, XL, ZeL and YZ performed the experiments. ZZ and $\mathrm{CK}$ conceived and designed the study. All authors have read and approved the final manuscript.

\section{Ethics approval and consent to participate}

All protocols associated with humans in the present study were approved by the Review Board of the First Hospital 
of China Medical University. All methods were performed in accordance with the relevant guidelines and regulations. Consent was obtained at the time of data collection.

\section{Patient consent for publication}

All patients provided consent.

\section{Competing interests}

The authors declare that they have no competing interests.

\section{References}

1. Fassnacht M, Kroiss M and Allolio B: Update in adrenocortical carcinoma. J Clin Endocrinol Metab 98: 4551-4564, 2013.

2. Fassnacht M, Johanssen S, Fenske W, Weismann D, Agha A, Beuschlein F, Führer D, Jurowich C, Quinkler M, Petersenn S, et al: Improved survival in patients with stage II adrenocortical carcinoma followed up prospectively by specialized centers J Clin Endocrinol Metab 95: 4925-4932, 2010.

3. Drougat L, Omeiri H, Lefèvre L and Ragazzon B: Novel insights into the genetics and pathophysiology of adrenocortical tumors. Front Endocrinol 6: 96, 2015

4. Soon PS, Gill AJ, Benn DE, Clarkson A, Robinson BG, McDonald KL and Sidhu SB: Microarray gene expression and immunohistochemistry analyses of adrenocortical tumors identify IGF2 and Ki-67 as useful in differentiating carcinomas from adenomas. Endocr Relat Cancer 16: 573-583, 2009.

5. Guillaud-Bataille M, Ragazzon B, de Reyniès A, Chevalier C, Francillard I, Barreau O, Steunou V, Guillemot J, Tissier F, Rizk-Rabin M, et al: IGF2 promotes growth of adrenocortical carcinoma cells, but its overexpression does not modify phenotypic and molecular features of adrenocortical carcinoma. PLoS One 9: e103744, 2014.

6. Wandoloski M, Bussey KJ and Demeure MJ: Adrenocortical cancer. Surg Clin North Am 89: 1255-1267, 2009.

7. Assié G,Letouzé E, Fassnacht M, Jouinot A, Luscap W, Barreau O, Omeiri H, Rodriguez S, Perlemoine K, René-Corail F, et al: Integrated genomic characterization of adrenocortical carcinoma. Nat Genet 46: 607-612, 2014

8. Lin SR, Lee YJ and Tsai JH: Mutations of the p53 gene in human functional adrenal neoplasms. J Clin Endocrinol Metab 78: 483-491, 1994

9. Hsu CH, Lee SC, Yang YC, Lian ST, Shin SJ and Lin SR: The p53 codon 249 mutant-derived from human functional adrenal tumors-can modify the cell shape of normal adrenocortical transfected cells. Cancer Lett 170: 63-71, 2001.

10. Tissier F, Cavard C, Groussin L, Perlemoine K, Fumey G, Hagneré AM, René-Corail F, Jullian E, Gicquel C, Bertagna X, et al: Mutations of beta-catenin in adrenocortical tumors: Activation of the Wnt signaling pathway is a frequent event in both benign and malignant adrenocortical tumors. Cancer Res 65: 7622-7627, 2005.

11. Clough $\mathrm{E}$ and Barrett $\mathrm{T}$ : The gene expression Omnibus database. Methods Mol Biol 1418: 93-110, 2016.

12. Lee JS: Exploring cancer genomic data from the cancer genome atlas project. BMB Rep 49: 607-611, 2016.

13. Gautier L, Cope L, Bolstad BM and Irizarry RA: Affy-analysis of Affymetrix GeneChip data at the probe level. Bioinformatics 20: 307-315, 2004

14. Ritchie ME, Phipson B, Wu D, Hu Y, Law CW, Shi W and Smyth GK: limma powers differential expression analyses for RNA-sequencing and microarray studies. Nucleic Acids Res 43: e47, 2015 .

15. Huang da W, Sherman BT and Lempicki RA: Systematic and integrative analysis of large gene lists using DAVID bioinformatics resources. Nat Protoc 4: 44-57, 2009.

16. Harris MA, Clark J, Ireland A, Lomax J, Ashburner M, Foulger R Eilbeck K, Lewis S, Marshall B, Mungall C, et al: The Gene Ontology (GO) database and informatics resource. Nucleic Acids Res 32: D258-D261, 2004.

17. Shannon P, Markiel A, Ozier O, Baliga NS, Wang JT, Ramage D, Amin N, Schwikowski B and Ideker T: Cytoscape: A software environment for integrated models of biomolecular interaction networks. Genome Res 13: 2498-2504, 2003.
18. Weiss LM, Medeiros LJ and Vickery AL: Pathologic features of prognostic significance in adrenocortical carcinoma. Am J Surg Pathol 13: 202-206, 1989.

19. Aubert S, Wacrenier A, Leroy X, Devos P, Carnaille B, Proye C, Wemeau JL, Lecomte-Houcke M and Leteurtre E: Weiss system revisited: A clinicopathologic and immunohistochemical study of 49 adrenocortical tumors. Am J Surg Pathol 26: 1612-1619, 2002.

20. Livak KJ and Schmittgen TD: Analysis of relative gene expression data using real-time quantitative PCR and the $2^{-\Delta \Delta C \mathrm{~T}}$ method. Methods 25: 402-408, 2001.

21. Liu T, Brown TC, Juhlin CC, Andreasson A, Wang N, Bäckdahl M, Healy JM, Prasad ML, Korah R, Carling T, et al: The activating TERT promoter mutation C228T is recurrent in subsets of adrenal tumors. Endocr Relat Cancer 21: 427-434, 2014.

22. Strausfeld U and Richter A: Simultaneous purification of DNA topoisomerase I and II from eukaryotic cells. Prep Biochem 19: 37-48, 1989.

23. Qian X, Song X, He Y, Yang Z, Sun T, Wang J, Zhu G, Xing W and You C: CCNB2 overexpression is a poor prognostic biomarker in Chinese NSCLC patients. Biomed Pharmacother 74: 222-227, 2015.

24. Qu Y,Li J, Cai Q and Liu B: Hec1/Ndc80 is overexpressed in human gastric cancer and regulates cell growth. J Gastroenterol 49: 408-418, 2014.

25. Ploeg M, Aben KK and Kiemeney LA: The present and future burden of urinary bladder cancer in the world. World J Urol 27: 289-293, 2009.

26. Wu KZ, Wang GN, Fitzgerald J, Quachthithu H, Rainey MD, Cattaneo A, Bachi A and Santocanale C: DDK dependent regulation of TOP2A at centromeres revealed by a chemical genetics approach. Nucleic Acids Res 44: 8786-8798, 2016.

27. Terashima M, Ichikawa W, Ochiai A, Kitada K, Kurahashi I, Sakuramoto S, Katai H, Sano T, Imamura $\mathrm{H}$ and Sasako M; ACTS-GC Group: TOP2A, GGH, and PECAM1 are associated with hematogenous, lymph node, and peritoneal recurrence in stage II/III gastric cancer patients enrolled in the ACTS-GC study. Oncotarget 8: 57574-57582, 2017.

28. de Resende MF, Vieira S, Chinen LT, Chiappelli F, da Fonseca FP, Guimarães GC, Soares FA, Neves I, Pagotty S, Pellionisz PA, et al: Prognostication of prostate cancer based on TOP2A protein and gene assessment: TOP2A in prostate cancer. J Transl Med 11: 36, 2013.

29. Kirk JS, Schaarschuch K, Dalimov Z, Lasorsa E, Ku S, Ramakrishnan S, Hu Q, Azabdaftari G, Wang J, Pili R, et al: Top2a identifies and provides epigenetic rationale for novel combination therapeutic strategies for aggressive prostate cancer. Oncotarget 6: 3136-3146, 2015.

30. Labbé DP, Sweeney CJ, Brown M, Galbo P, Rosario S, Wadosky KM, Ku SY, Sjöström M, Alshalalfa M, Erho N, et al: TOP2A and EZH2 provide early detection of an aggressive prostate cancer subgroup. Clin Cancer Res 23: 7072-7083, 2017.

31. Mu XC, Tran TA, Ross JS and Carlson JA: Topoisomerase II-alpha expression in melanocytic nevi and malignant melanoma. J Cutan Pathol 27: 242-248, 2000

32. Holden JA and Townsend JJ: DNA topoisomerase II-alpha as a proliferation marker in astrocytic neoplasms of the central nervous system: Correlation with MIB1 expression and patient survival. Mod Pathol 12: 1094-1100, 1999.

33. Costa MJ, Hansen CL, Holden JA and Guinee D Jr: Topoisomerase II alpha: Prognostic predictor and cell cycle marker in surface epithelial neoplasms of the ovary and peritoneum. Int J Gynecol Pathol 19: 248-257, 2000.

34. Dingemans AM, Witlox MA, Stallaert RA, van der Valk P, Postmus PE and Giaccone G: Expression of DNA topoisomerase IIalpha and topoisomerase IIbeta genes predicts survival and response to chemotherapy in patients with small cell lung cancer. Clin Cancer Res 5: 2048-2058, 1999.

35. Depowski PL, Rosenthal SI, Brien TP, Stylos S, Johnson RL and Ross JS: Topoisomerase IIalpha expression in breast cancer: Correlation with outcome variables. Mod Pathol 13: 542-547,2000.

36. Park SH, Yu GR, Kim WH, Moon WS, Kim JH and Kim DG: NF-Y-dependent cyclin B2 expression in colorectal adenocarcinoma. Clin Cancer Res 13: 858-867, 2007.

37. Shubbar E, Kovács A, Hajizadeh S, Parris TZ, Nemes S, Gunnarsdóttir K, Einbeigi Z, Karlsson P and Helou K: Elevated cyclin B2 expression in invasive breast carcinoma is associated with unfavorable clinical outcome. BMC Cancer 13: 1, 2013.

38. Lei CY, Wang W, Zhu YT, Fang WY and Tan WL: The decrease of cyclin B2 expression inhibits invasion and metastasis of bladder cancer. Urol Oncol 34: 237.e1-10, 2016. 
39. Zhou L, Du Y, Kong L, Zhang X and Chen Q: Identification of molecular target genes and key pathways in hepatocellular carcinoma by bioinformatics analysis. Onco Targets Ther 11: 1861-1869, 2018.

40. Yoo TY, Choi JM, Conway W, Yu CH, Pappu RV and Needleman DJ: Measuring NDC80 binding reveals the molecular basis of tension-dependent kinetochore-microtubule attachments. Elife 7: e36392, 2018.

41. Wu G, Qiu XL, Zhou L, Zhu J, Chamberlin R, Lau J, Chen PL and Lee WH: Small molecule targeting the Hec1/Nek2 mitotic pathway suppresses tumor cell growth in culture and in animal. Cancer Res 68: 8393-8399, 2008.

42. Bièche I, Vacher S, Lallemand F, Tozlu-Kara S, Bennani H, Beuzelin M, Driouch K, Rouleau E, Lerebours F, Ripoche H, et al: Expression analysis of mitotic spindle checkpoint genes in breast carcinoma: Role of $\mathrm{NDC} 80 / \mathrm{HECl}$ in early breast tumorigenicity, and a two-gene signature for aneuploidy. Mol Cancer 10: 23, 2011.
43. Huang LY, Chang CC, Lee YS, Chang JM, Huang JJ, Chuang SH, Kao KJ, Lau GM, Tsai PY, Liu CW, et al: Activity of a novel Hec1-targeted anticancer compound against breast cancer cell lines in vitro and in vivo. Mol Cancer Ther 13: 1419-1430, 2014. 44. Diaz-Rodríguez E, Sotillo R, Schvartzman JM and Benezra R: Hecl overexpression hyperactivates the mitotic checkpoint and induces tumor formation in vivo. Proc Natl Acad Sci USA 105: 16719-16724, 2008.

45. Puisieux A, Galvin K, Troalen F, Bressac B, Marcais C, Galun E, Ponchel F, Yakicier C, Ji J and Ozturk M: Retinoblastoma and p53 tumor suppressor genes in human hepatoma cell lines. FASEB J 7: 1407-1413, 1993. 